\title{
Outcome of Patients with Hepatocellular Carcinoma Listed for Liver Transplantation Within the Eurotransplant Allocation System
}

\author{
Michael Adler, ${ }^{1}$ Filip De Pauw, ${ }^{2}$ Pierre Vereerstraeten, ${ }^{1}$ Agnese Fancello, ${ }^{1}$ Jan Lerut, ${ }^{3}$ Peter Starkel, ${ }^{3}$ \\ Hans Van Vlierberghe, ${ }^{4}$ Roberto Troisi, ${ }^{4}$ Vincent Donckier, ${ }^{1}$ Olivier Detry, ${ }^{5}$ Jean Delwaide, ${ }^{5}$ \\ Peter Michielsen, ${ }^{2}$ Thierry Chapelle, ${ }^{2}$ Jacques Pirenne, ${ }^{6}$ and Frederik Nevens ${ }^{6}$ \\ ${ }^{1}$ Medico-Surgical Departments of Gastroenterology and Hepatopancreatology, Erasme Hospital, Université \\ Libre de Bruxelles, Brussels, Belgium; ${ }^{2}$ University Hospital Antwerp, Antwerp, Belgium; ${ }^{3}$ Université Catholique \\ de Louvain Brussels, Brussels, Belgium; ${ }^{4}$ Ghent University Hospital, Ghent, Belgium; ${ }^{5}$ University of Liège, Liège, \\ Belgium; and ${ }^{6}$ Universitaire Ziekenhuizen Gasthuisberg Leuven, Leuven, Belgium
}

\begin{abstract}
Although hepatocellular carcinoma (HCC) has become a recognized indication for liver transplantation, the rules governing priority and access to the waiting list are not well defined. Patient- and tumor-related variables were evaluated in 226 patients listed primarily for $\mathrm{HCC}$ in Belgium, a region where the allocation system is patient-driven, priority being given to sicker patients, based on the Child-Turcotte-Pugh (CTP) score. Intention-to-treat and posttransplantation survival rates at 4 years were 56.5 and $66 \%$, respectively, and overall HCC recurrence rate was $10 \%$. The most significant predictors of failure to receive a transplant in due time were baseline CTP score equal to or above 9 (relative risk [RR] 4.1; confidence interval [Cl]: 1.7-9.9) and $\alpha$ fetoprotein above $100 \mathrm{ng} / \mathrm{mL}$ (RR 3.0; Cl: 1.2-7.1). Independent predictors of posttransplantation mortality were age equal to or above 50 years (RR 2.5; Cl: 1.0-3.7) and United Network for Organ Sharing pathological tumor nodule metastasis above the Milan criteria (RR 2.1; Cl: 1.0-5.9). Predictors of recurrence (10\%) were $\alpha$ fetoprotein above $100 \mathrm{ng} / \mathrm{mL}$ (RR 3.2; Cl:1.1-10) and vascular involvement of the tumor on the explant (RR 3.6; Cl: 1.1-11.3). Assessing the value of the pretransplantation staging by imaging compared to explant pathology revealed 34\% accuracy, absence of carcinoma in $8.3 \%$, overstaging in $36.2 \%$, and understaging in $10.4 \%$. Allocation rules for HCC should consider not only tumor characteristics but also the degree of liver impairment. Patients older than 50 years with a stage above the Milan criteria at transplantation have a poorer prognosis after transplantation. Liver Transpl 14:526-533, 2008. $\odot 2008$ AASLD.
\end{abstract}

Received 15 February 2007; accepted 16 October 2007.

Liver transplantation (LTX) is now accepted as a curative modality for early stage hepatocellular carcinoma (HCC) on the basis of excellent 5-year survival rates (71\%-75\%). These rates are comparable to those for patients with advanced cirrhosis without malignancies, ${ }^{1}$ Even outside the Milan criteria ${ }^{2}$ but within the moderate expansion criteria of the University of California, San Francisco (UCSF), patients with HCC have an acceptable 5-year period of survival. ${ }^{3}$
Nevertheless, the results of LTX for HCC in the literature are still discrepant. They derive from series including a heterogeneous mixture of individuals in terms of liver function, tumor stage, and definition of outcomes (such as dropout for progressive malignancy, recurrence of malignancy, and assessment of survival on an intention-to-treat basis versus posttransplantation). The use of pre-LTX adjuvant therapy such as liver resection, chemoembolization, or radiofrequency abla-

Abbreviations: $\alpha \mathrm{FP}, \alpha$ fetoprotein; AJCC, American Joint Committee on Cancer; CI, confidence interval; CTP, Child-Turcotte-Pugh; CT, computed tomography; cTNM, clinical tumor-node-metastasis staging; HCC, hepatocellular carcinoma; LTX, liver transplantation; MELD, Model for End-Stage Liver Disease; pTNM, pathological tumor-node-metastasis staging; RR, relative risk; TNM, tumornode-metastasis staging; UCSF, University of California, San Francisco; UNOS, United Network for Organ Sharing; UICC, International Union Against Cancer (Union Internationale contre le Cancer). Part of this work was presented at the European Association for the Study of the Liver, Vienna, 2006.

Address reprint requests to Michael Adler, M.D., Ph.D., Department of Gastroenterology and Hepatopancreatology, Hôpital Erasme, 808 route de Lennik, 1070 Brussels, Belgium. Telephone: 32-2-555.37.14; FAX: 32-2-555.46.97; E-mail: michael.adler@erasme.ulb.ac.be

DOI 10.1002/lt.21399

Published online in Wiley InterScience (www.interscience.wiley.com). 
tion (either as a downstaging procedure or to control the evolution of the tumor while on the waiting list), may also constitute an important confounding variable. Studies are often small and single-center, and above all, liver allocation policies for HCC vary greatly from one allocation organization to another. The shortage of organs, combined with the increased incidence of HCC in the United States and Europe, largely due to the medical consequences of the hepatitis $\mathrm{C}$ epidemic, make it more crucial than ever to optimize the criteria of both selection and priority for transplantation. Various strategies have been adopted by the transplant community, ranging from no priority for HCC (such as in the current Eurotransplant system), to a center-oriented system by which the local team chooses the recipient who could benefit most from the donor organ (a procedure used in most other European centers) or to the new allocation policy based on the Model for End-Stage Liver Disease (MELD) adopted in the United States since February $2002 .{ }^{4}$ The latter system, based on the estimated risk of tumor progression within the Milan criteria, has been shown to reduce the dropout rate and increase the transplantation rate, while maintaining an excellent post-LTX outcome. ${ }^{4,5}$ However, all these different sets of selection and priority criteria introduce biases that influence the outcome of patients with HCC.

We therefore set out to identify, in a large multicenter study, the predictive factors of the various outcomes for HCC patients on the waiting list, with the aim of offering the possibility of LTX to as many of those most likely to be cured as possible. The fact that the Eurotransplant allocation system used is patient-driven, but outside the MELD system, gave us the unique opportunity to estimate their natural history while on the waiting list.

\section{PATIENTS AND METHODS}

Between October 1, 1999 and October 1, 2004, 272 HCC patients belonging to the 6 Belgian transplant centers, grouped into the Belgian Liver Intestine Committee of the Belgian Transplant Society, were consecutively listed for cadaveric LTX within the framework of Eurotransplant, a foundation responsible for the allocation of donor organs in Austria, Belgium, Germany, Luxembourg, the Netherlands, and Slovenia. During the same period, 955 patients with chronic liver disease without malignancy were listed, so that our HCC population constituted 29\% of the total Belgian series of patients listed. The charts of these patients were retrospectively reviewed. During the study period, no listing priority based on HCC characteristics alone was possible. According to the Eurotransplant allocation rules, as from July 2000, only cirrhotic patients with a ChildTurcotte-Pugh (CTP) score $\geq 10$ and complications were given priority and, from September 2003 the cutoff point for this score was raised to $\geq 11$. $^{6}$

Only patients with a diagnosis of $\mathrm{HCC}$ at listing were included in the present series. Their diagnosis was based on parameters similar to those proposed by the European Association for the Study of Liver diseases ${ }^{7}$ : either histological proof, or the presence of a nodule with a diameter exceeding $2 \mathrm{~cm}$, identified by ultrasonography and confirmed to be hypervascular, either at computed tomography (CT) or magnetic resonance imaging or by 1 imaging study combined with an $\alpha$ fetoprotein $(\alpha \mathrm{FP})$ level above $400 \mathrm{ng} / \mathrm{mL}$. HCC was considered as the primary diagnosis $(n=226)$ when the cancer was the reason for transplantation, and the secondary diagnosis $(n=46)$ when decompensated cirrhosis was the indication, HCC being detected incidentally during the prelisting workup.

Our study focused on the first group, because it is the most prevalent $(226 / 272,83 \%)$, for more homogeneous results interpretation and to study the natural history of the malignancy without the direct bias of the degree of liver impairment. Patients with HCC were selected for transplantation according to the Milan criteria ${ }^{2}$ as requested by Eurotransplant and this was accepted by the 6 transplant centers represented by the Belgian Liver Intestine Committee, a national organization, recognized by Eurotransplant. Patients with extrahepatic spread, assessed by bone scan and chest CT and/or vascular invasion were excluded. During the waiting period for LTX, imaging was repeated every 3 to 6 months. Delisting for tumor progression was decided upon detection of either major vascular involvement or extrahepatic spread.

Adjuvant therapy before listing or while waiting was given to 123 of the 226 patients (54\%), and consisted of transarterial chemoembolization in 93 (76\%), percutaneous alcoholization in $16(13 \%)$, liver resection in 9 $(7 \%)$, and radiofrequency ablation in $5(4 \%)$.

Because of the absence of clear guidelines, the magnitude of incorrect assessment of HCC staging by the current imaging methods, and the availability of potentially useful treatments, which either downstage the tumor or limit its progression, ${ }^{8}$ these were decided upon a case-by-case basis during the weekly multidisciplinary medicosurgical conference in each center. In particular, they were implemented in patients outside the Milan criteria and/or in those who had tumor progression. This category of patients was also listed for a marginal graft.

After listing for HCC, various distinct clinical outcomes were considered. Before LTX, these comprised the total number of failures (that is, death before delisting and/or delisting because of tumor progression) and, after LTX, overall mortality and HCC recurrence, while the patients still alive were evaluated at the last follow-up (April 1, 2005).

Thirteen categorical or continuous variables concerning the prognostic value of all these outcomes were analyzed. The clinical and demographic variables considered were age at listing and at transplantation, gender, transplant center, waiting time, blood group, year of listing, year of LTX, CTP score, ${ }^{9}$ and MELD score. ${ }^{10}$

Tumor-related variables were $\alpha \mathrm{FP}$ at baseline, use of prereferral or postreferral adjuvant therapy or no therapy, the number of nodules, the size of the largest nodule, the presence or absence of vascular invasion, and tumor-node-metastasis (TNM) staging according to 
the American Liver Tumor Study group modification adopted by the United Network for Organ Sharing $(\mathrm{UNOS})^{11}$ and recently modified further by Yao et al. ${ }^{12}$ Tumor staging was based on preoperative imaging UNOS clinical tumor-node-metastasis (cTNM) staging and was evaluated at the time of listing and, after LTX, from explant pathology using UNOS pathological tumor-node-metastasis (pTNM) staging and American Joint Committee on Cancer (AJCC)/International Union Against Cancer (Union Internationale contre le Cancer, UICC) criteria. ${ }^{13}$ Explanted liver was examined by experienced local pathologists using 1-cm-thick sections. One of the 179 explanted liver specimens could not be staged. The number of nodules, maximal tumor size, and evidence of macrovascular involvement allowed the evaluation of UNOS cTNM and pTNM, and the differences between them.

The UNOS cTNM and pTNM staging used for our study comprised the following: no HCC: absence of HCC on the pathological specimen; TO: evidence of tumoral necrosis within the explant, the disappearance of hypervascularity on follow-up imaging after adjuvant therapy, or tumor resection before transplantation; $\mathrm{T} 1$ : single nodule $<2.0 \mathrm{~cm}$; T2: single nodule $2-5 \mathrm{~cm}$ or 2 or 3 nodules $\leq 3 \mathrm{~cm}$ (that is, Milan criteria); T3: single nodule $>5 \mathrm{~cm}$ or 2 or 3 nodules, at least one $>3.0 \mathrm{~cm}$; T3A: single nodule $\leq 6.5 \mathrm{~cm}$ or $\leq 3$ nodules with the largest lesion $\leq 4.5 \mathrm{~cm}$ and total tumor diameter $\leq 8 \mathrm{~cm}$ (that is, UCSF criteria); T3B: T3 other than T3A; T4A: 4 or more nodules of any size; and T4B: T2, T3, or T4A plus macroscopic intrahepatic portal or hepatic vein involvement. The definition of the AJCC/UICC pTNM was the following: TO, no evidence of tumor; T1, solitary tumor without vascular invasion; T2, solitary tumor with vascular invasion or multiple tumors, none more than $5 \mathrm{~cm}$; T3, multiple tumors more than $5 \mathrm{~cm}$ or tumor involving a major branch of the portal or hepatic vein(s); and T4, tumor(s) with direct invasion of adjacent organs other than the gallbladder or with perforation of visceral peritoneum. Tumor grading according to the Edmonson criteria ${ }^{14}$ was available in 154 of the 178 pathological reports.

The liver transplant procedure involved only cadaveric donors.

Immunosuppressive therapy after LTX consisted of a double or triple drug regimen of tacrolimus combined with steroids and/or mycophenolate mofetil in the case of renal failure. Tacrolimus was switched to cyclosporine in the case of unstable diabetes or neurologic side effects. Steroids were tapered gradually and discontinued within 3 months.

All patients were followed regularly at the outpatient clinic. The frequency of visits varied according to the patient's condition and type of complications.

Screening for HCC recurrence after LTX was done by ultrasound and $\alpha \mathrm{FP}$ measurement every 6 months, abdominal CT every year, with bone scan, magnetic resonance imaging, or chest CT if necessary. No adjuvant chemotherapy was administered.

\section{Statistical Analysis}

Univariate and multivariate analyses of the potential prognostic variables were performed for the various outcomes, that is, risk of death and dropout on the waiting list before LTX, death, and recurrence of HCC after LTX.

In each analysis, failures due to events other than the event of interest were treated as censored observations. In the univariate analysis, categorical variables were compared using the chi-square or Fisher's exact tests, as appropriate. Continuous variables were compared using the nonparametric Mann-Whitney test or the Student $t$ test (if they were Gaussian), or logarithmically transformed for the skewed variables. They were categorized in two groups, the cutoff value being selected in a pragmatic way in order to obtain the highest possible statistical significant difference between the survival curves. To assess the risk factors for the different outcomes, Cox hazard regression models were constructed and the relative risks estimated, together with their 95\% confidence intervals.

Only variables which emerged with a $P$ value $<0.1$ after univariate analysis were included in the Cox model. ${ }^{15}$ They were selected stepwise for statistical significance. The proportional assumption of the Cox model was graphically verified by the linear relationship between the $\log _{n}(\ln )$ of cumulative events and the $\ln$ of time. ${ }^{16}$ Graphic displays of the results were obtained using the actuarial method and the survival curves for a given prognostic factor were adjusted using stratification in order to account for the influence of the other factors, thus avoiding confounding biases. Calculations were carried out using the StatView program. ${ }^{17}$

\section{RESULTS}

\section{Baseline Demographic Data Including Patient and Tumor Characteristics}

The general characteristics of the 226 patients with primary HCC are given in Table 1.

Most patients were men (79\%), and $42 \%$ had hepatitis $\mathrm{C}$ virus as the underlying liver disease. Median CTP and MELD scores at listing were 6.7 and 9.3, respectively. The number of patients listed yearly was fairly constant, taking into account the fact that in 1999 and 2004, the inclusion periods considered were 3 and 9 months, respectively.

At listing, 149 patients (66\%) were candidates for LTX according to the Milan criteria (that is, T1 or T2), 29 (13\%) were within the UCSF criteria and 48 (21\%) did not fulfill the UCSF or Milan criteria and were listed for a marginal graft for which no other recipient was available for that organ.

\section{Survival According to Intention-to-Treat and Post-LTX}

The 6-month and 1-, 2-, 3-, and 4-year survival rates for the 226 patients listed with primary $\mathrm{HCC}$, according to intention-to-treat analysis (time zero point being the 
TABLE 1. Baseline Characteristics of the 226 Patients with Primary HCC Listed for Transplantation

Median age, years (range)

Gender: male/female (\%)

ABO blood group n: O/A/B/AB

Transplant center: KUL/GUH/UHA/UCL/ULB/ULg

Etiology of underlying liver disease n (\%): HCV/alcohol/other

Listing per year n: 1999/2000/2001/2002/2003/2004

UNOS TNM staging at listing $\mathrm{n}(\%)$ : T1/T2/T3A/T3B/T4A

Adjuvant therapy $\mathrm{n}=123$ (54\%) $\mathrm{n}(\%)$ : TACE/alcoholization/resection/RF

Median Child-Turcotte-Pugh score (range)

Median MELD score (range)

$$
\begin{array}{r}
58(17-72) \\
173(77) / 57(23) \\
78 / 111 / 28 / 9 \\
92 / 32 / 9 / 46 / 24 / 23 \\
96(42) / 65(29) / 65(29) \\
8 / 42 / 30 / 46 / 64 / 36 \\
20(9) / 129(57) / 29(13) / 11(5) / 37(16) \\
93(76) / 16(13) / 9(7) / 5(4) \\
6.7(5-13) \\
9.3(6-30)
\end{array}
$$

Abbreviations: GUH, Ghent University Hospital; HBV, hepatitis B virus; HCC, hepatocellular carcinoma; HCV, hepatitis C virus; KUL, Katholieke Universiteit Leuven; MELD, Model for End-Stage Liver Disease; RF, radiofrequency ablation; TACE, transarterial chemoembolisation; TNM, tumour node metastasis; UCL, Université Catholique de Louvain; ULB, Université Libre de Bruxelles; ULg, Université de Liège; UZA, Universiy Hospital Antwerpen.

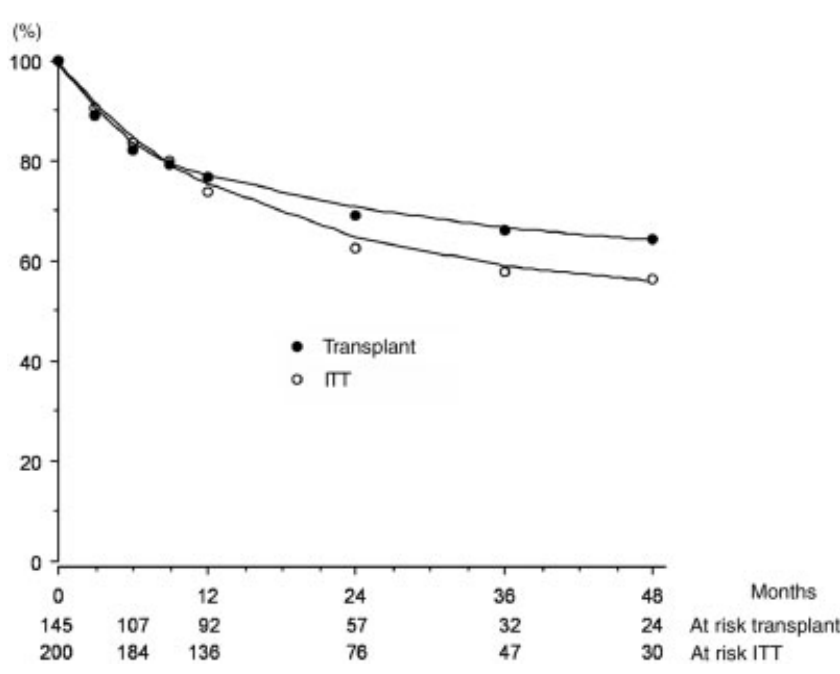

Figure 1. Patient survival after liver transplantation (TRANSPLANT) and according to intention to treat (ITT).

inclusion of the subject on the waiting list) were 84,74 , 63,58 , and 56\%, respectively. For those actually receiving transplantation, the corresponding survival rates were $84,79,72,69$, and $66 \%$, respectively (Fig. 1). The $10 \%$ difference between the 2 curves reflected failure of the listing due to dropout, or death before dropout.

\section{Probability of Pre- and Post-LTX Outcomes and Prognostic Factors}

The actuarial probabilities of the most pertinent preLTX events in the 226 patients listed with primary HCC, that is, failures to get a transplant and chance of receiving a graft, show a $24 \%$ and $78 \%$ rate at 18 months, respectively (Fig. 2). The results of stepwise Cox regression analysis of the impact of the 13 baseline variables on these outcomes are given in Table 2 , with their cutoff values, regression coefficient, standard error, statistical significance, relative risk, and 95\% confidence intervals.

Of the 226 patients listed, 30 were delisted (19 for

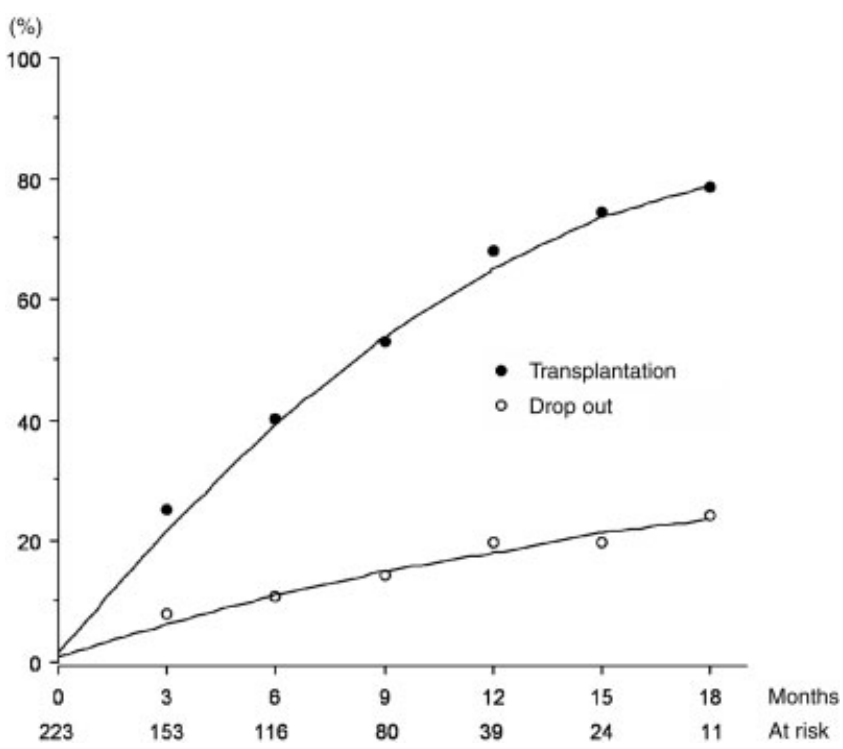

Figure 2. Cumulative probability (\%) of transplantation and dropout after inclusion on the waiting list for patients on the waiting list with primary HCC.

tumor progression, 2 for severe liver failure, 1 for social reasons, 5 for noncompliance, and 3 for responding well to adjuvant therapy). Ten patients died before being delisting ( 3 of sepsis, 2 of liver failure, 2 of cardiovascular events, 1 of tumor progression, 1 of cytomegalovirus hepatitis, and 1 of unknown reason). Twentynine $(12.8 \%)$ patients, including the 19 delisted for tumor progression and the 10 who died before delisting, were thus considered as pre-LTX failures.

Based on the multivariate analysis, CTP score $\geq 9$, (relative risk [RR] 4.1), $\alpha \mathrm{FP}>100 \mathrm{ng} / \mathrm{mL}$ at baseline (RR 3.0), and preoperative adjuvant therapy (RR 2.5) were independent risk factors for a failure to get a transplant in time (Table 2). One hundred forty-five of the $226(64 \%)$ patients were transplanted after a median waiting period of 4 months (range, 0-27.2). The waiting time (mean \pm standard error of the mean) increased steadily with the year of listing: 1999, $2.6 \pm$ 


\begin{tabular}{|c|c|c|c|c|c|c|}
\hline Outcome & Covariate & $\begin{array}{r}\text { Reference } \\
\text { Category }\end{array}$ & $\begin{array}{r}\text { Regression } \\
\text { Coefficient }\end{array}$ & $\begin{array}{r}\text { Standard } \\
\text { Error }\end{array}$ & $P$ Value & $\begin{array}{r}\text { Relative Risk } \\
(95 \% \mathrm{CI})\end{array}$ \\
\hline \multirow[t]{3}{*}{$\begin{array}{l}\text { Pre-LTX failures } \\
\quad(\mathrm{n}=29)\end{array}$} & Child-Turcotte-Pugh score & $9-13$ & 1.411 & 0.447 & 0.002 & $4.1(1.7-9.9)$ \\
\hline & $\alpha \mathrm{FP}(\mathrm{ng} / \mathrm{mL})$ & $>100$ & 1.089 & 0.442 & 0.014 & $3.0(1.2-7.1)$ \\
\hline & Preoperative therapy & Yes & 0.924 & 0.442 & 0.037 & $2.5(1.1-6.0)$ \\
\hline \multirow[t]{2}{*}{$\begin{array}{l}\text { Recurrence of HCC after } \\
\quad \operatorname{LTX}(\mathrm{n}=14)\end{array}$} & $\alpha \mathrm{FP}(\mathrm{ng} / \mathrm{mL})$ & $>100$ & 1.178 & 0.572 & 0.039 & $3.2(1.1-10.0)$ \\
\hline & Vascular involvement & Yes & 1.278 & 0.587 & 0.029 & $3.6(1.1-11.3)$ \\
\hline \multirow{2}{*}{$\begin{array}{l}\text { Deaths after LTX } \\
\quad(\mathrm{n}=45)\end{array}$} & Patient age (years) & $\geq 50$ & 0.911 & 0.444 & 0.040 & $2.5(1.0-5.9)$ \\
\hline & UNOS pTNM & $>2$ & 0.680 & 0.326 & 0.037 & $2.1(1.0-3.7)$ \\
\hline
\end{tabular}

Abbreviation: CI, confidence interval.

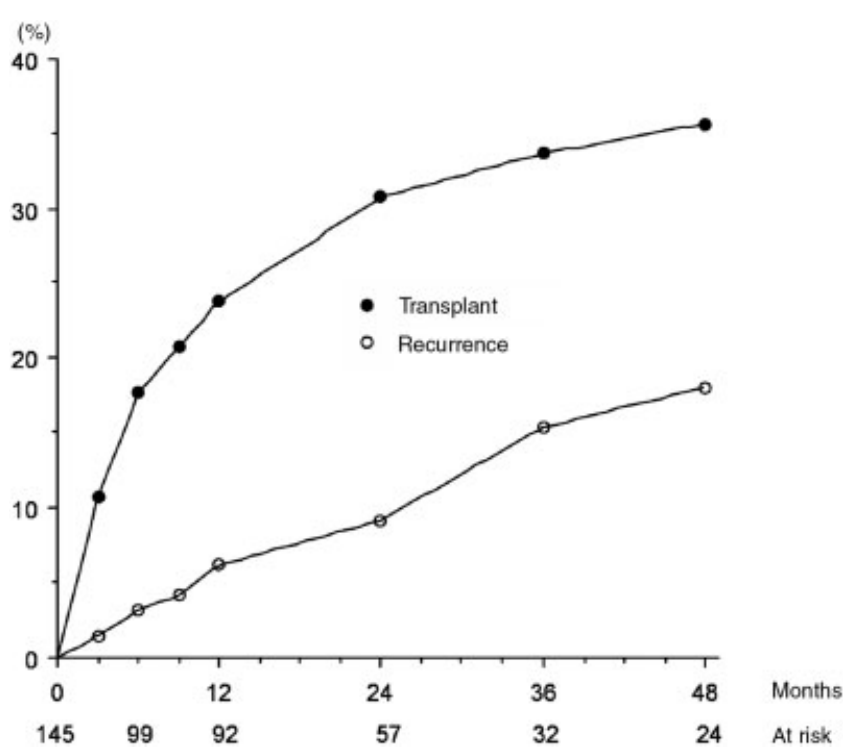

Figure 3. Actuarial cumulative rate of mortality and HCC recurrence after transplantation.

$0.7 ; 2000,4.2 . \pm 0.9 ; 2001,6.8 \pm 1.1 ; 2002,7.1 \pm 0.8$; and 2003-2004, $3.7 \pm 1.7$ months.

\section{Probabilities of Post-LTX Outcomes and Prognostic Factors}

The actuarial post-LTX risks of overall mortality and probability to remain free of $\mathrm{HCC}$ recurrence for the 145 patients actually transplanted are illustrated in Fig. 3, showing a rate of death and recurrence of $34 \%$ and $17 \%$ at 4 years. Patient survival after LTX is thus $66 \%$ at 4 years. HCC recurred in 14 patients (10\%), after a mean period $11 \pm 3.8$ months (range, $2-46$ ). Two independent risk factors predicted HCC recurrence: $\alpha \mathrm{FP}>100 \mathrm{ng} / \mathrm{m}$ and presence of vascular invasion on the hepatectomy specimen, with RRs of 3.2 and 3.6, respectively (Table 2). Forty-five patients died after LTX, because of sepsis in 13, recurrent $\mathrm{HCC}$ in 15, cardiovascular problems in 3 , perioperative problems in $2, \mathrm{HCV}$ recurrence in 2 , gastrointestinal hemorrhage in 1 , liver failure in 1 , de novo neoplasms in 5, and unknown reasons in 3. Only UNOS pTNM above T2 (RR 2.1) and age above 50 years (RR 2.5) were significant predictors of post-LTX death.

When the AJCC/UICC TNM was included in the Cox multivariate regression analysis, it did not add significant independent discriminative power $(P=0.48)$.

\section{Correlation Between Clinical and Pathological TNM}

The findings by pre-LTX imaging at the time of listing were different from the pathological findings in a significant number of patients, based on the 144 hepatectomy specimens (data not shown). The mean and median periods between UNOS cTNM at listing and UNOS pTNM were 5.4 and 4.4 months, respectively. No tumor, TO stage, same staging, understaging (more lesions in the explanted liver, that is, UNOS pTNM, than those observed by preoperative imaging, that is, UNOS cTNM), and overstaging (more lesions on UNOS cTNM than UNOS pTNM) were observed in $8.3 \%(12 / 144)$, $11.1 \%$ (16/144), 34\% (49/144), 10.4\% (15/144), and $36.2 \%$ (52/144), respectively.

\section{DISCUSSION}

In this large multicenter series of $\mathrm{HCC}$ patients from a European region where only patients with decompensated cirrhosis receive priority for LTX, we have identified a subset of patients at high risk of not receiving transplantation either because of death before delisting or dropout because of tumor progression. Their identification is based on tumor characteristics and the degree of liver impairment caused by the underlying liver disease.

The importance of an intention-to-treat analysis to evaluate the benefit of LTX as a treatment of HCC was first suggested by Llovet et al. ${ }^{18}$ and was subsequently emphasized by other groups. ${ }^{19,20}$ On the basis of our intention-to-treat analysis, we obtained a $10 \%$ difference in comparison with the 66\% 4-year actuarial survival, which reflected the natural history of our HCC patients on the waiting list, for whom there was no 
priority bias. For the patients actually receiving transplantation, our 6-month, 1-, 2-, 3-, and 4-year longterm survival rates were $84,79,72,69$, and $66 \%$, respectively, together with a low (10\%) actuarial incidence of recurrent $\mathrm{HCC}$, results which are comparable to those recently reported..$^{21}$ Our results confirm that $\alpha \mathrm{FP}$ is an important predictor of poor pre-LTX clinical outcome $^{22,23}$ and suggests that this simple, objective biological parameter could be used to refine the transplant allocation policy for HCC patients listed for LTX. Apart from $\alpha \mathrm{FP}$, we showed that the degree of liver impairment, a determining element for the organ allocation decisions, still represents a significant risk factor for failure to get a transplant in due time. This is a striking observation that has already been noted by an Italian ${ }^{24}$ and a Chinese ${ }^{25}$ group, outside the MELD priority policy, reporting that the dropout rate before transplantation was related to CTP score, regardless of the preoperative diagnosis of HCC. Our analysis indicates that the best cutoff point for defining risk of liver failure, in the presence of primary $\mathrm{HCC}$, is a CTP score of 9 or more. This underlines the fact that the critical threshold may be lower for HCC than for patients with cirrhosis without HCC, for whom the CTP has been estimated at $11 .^{26}$ It must be emphasized that for our patients listed for HCC and not for end-stage liver disease, the MELD score was not a predictive factor of LTX failure, when competing with the CTP score in the multivariate analysis. Moreover, it was not statistically significant $(P=0.67$; data not shown) in the univariate analysis. The reasons for this observation are probably related to the high power of serum creatinine in the MELD score, a parameter not directly measuring liver failure in its early stage; this confirms recent data showing that MELD score is an excellent predictor of short-term mortality on the waiting list ${ }^{27}$ only when this score is high, reflecting advanced liver disease associated with renal failure.

Our data demonstrate that the true stage of HCC was underestimated in $10.4 \%$ of our patients, the values reported in the literature being 20 to $30 \% .^{20}$ Absence of $\mathrm{HCC}$ on the hepatectomy specimen was seen in $8.3 \%$, this being observed in 10 to $31 \%$ for UNOS TNM stage 1 lesions in the literature. ${ }^{4,28}$ Overstaging was observed in a high percentage of cases (36\%), thus confirming that the diagnostic accuracy and adequate characterization of nodules in patients with cirrhosis is low with the currently used imaging techniques. ${ }^{29,30}$ This suggests performing more biopsies of sizable nodules in cirrhosis, ${ }^{31}$ but the lack of sensitivity, potential risks, and difficult access to the lesion, as well as the risk of seeding, are major objections.

In our study, adjuvant therapy, comprising mostly chemoembolization, was more detrimental than beneficial in increasing the chance of being transplanted. Possible reasons for the absence of a positive effect of adjuvant therapies might be potential selection biases, due to its use in more advanced disease and the harmful effects of such therapies. ${ }^{32-35}$ Thus, at the present time, the role of adjuvant therapy remains to be proven and trials comparing treatment versus no treatment for patients on the waiting list are needed. ${ }^{8}$ As the overall waiting period was short for our series, it was not a significant prognostic factor of post-LTX events. When the waiting period exceeded 12 months, we observed, as seen in Fig. 2, that the failure rate increased above 20\%, thus confirming other reports. ${ }^{36}$

The most powerful and significant predictor of death after LTX was patient age and a high risk (greater than T2) UNOS pTNM stage, in agreement with previous reports. ${ }^{37-40}$ The negative impact of older age on patient survival has been emphasized in large series but they did not include an HCC population. ${ }^{41}$ If our data are confirmed by others, this will suggest that, unless marginal donors are considered, expanding the criteria above the Milan criteria will only be justified for patients less than 50 years old, in order to keep the 5-year survival above the cutoff point of $50 \% .{ }^{42}$ Our study showed that the pTNM classification proposed by the UICC and the AJCC did not add significant independent prognostic value compared to the UNOS pTNM for evaluating post-LTX survival. Besides this, the interest in the latter is that it can be evaluated both on explant pathology and on preoperative imaging and it incorporates the Milan (UNOS T2) as well as the UCSF (UNOS T3A) staging criteria, which are now well accepted and largely applied as an estimation of tumor burden. ${ }^{2,3}$ Only HCC patients meeting UNOS T2 criteria by imaging are currently eligible for receiving priority listing for LTX under the MELD model in the United States and, since January 1, 2007, also in the Eurotransplant group.

In comparison with other series in which $\mathrm{HCC}$ recurrence after LTX varies from 10 to $50 \%,{ }^{43,44}$ our $10 \%$ rate is low, even though $34 \%$ of the patients were listed outside the Milan criteria and 21\% outside Yao's criteria. Only vascular invasion or its surrogate marker, $\alpha \mathrm{FP}$ was able to alter the prognosis by causing recurrence, in a minority of patients. This is an argument favoring the concept of modest expansion of the Milan criteria. Another reason could be in relation with the poor staging capability of preoperative imaging, demonstrated by this series and others.

In conclusion, both tumor characteristics and the degree of liver impairment, with a CTP equal or higher than 9, should be taken into consideration when offering priority on the waiting list for patients with cirrhosis with HCC.

Older patients with an HCC above the Milan criteria based on explant pathology have a poorer prognosis after transplantation. However, this category of patients is difficult to identify at listing because of the poor correlation between preoperative imaging and explant pathological stage. Our data may help in making policy decisions regarding liver allocation for patients with $\mathrm{HCC}$, in particular in the European regions, where there is currently no priority for HCC patients on the waiting list.

\section{ACKNOWLEDGMENT}

We thank F. Roggen, L. Colenbie, P. Finet, E. De Gendt, and $\mathrm{G}$. Bonduel for their invaluable help in collecting 
the data, and Drs. R. Aerts, J.B. de Hemptinne, J. de Ville de Goyet, M. Gelin, P. Honoré, and D. Ysebaert for allowing us to review their data.

\section{REFERENCES}

1. Befeler AS, Hayashi PH, Di Bisceglie AM. Liver transplantation for hepatocellular carcinoma. Gastroenterology 2005; 128:1752-1764.

2. Mazzaferro V, Regalia E, Doci R, Andreola S, Pulvirenti A, Bozzetti F, et al. Liver transplantation for the treatment of small hepatocellular carcinomas in patients with cirrhosis. N Engl J Med 1996;334:693-699.

3. Yao FY, Ferrell L, Bass NM, Bacchetti P, Ascher NL, Roberts JP. Liver transplantation for hepatocellular carcinoma: comparison of the proposed UCSF criteria with the Milan criteria and the Pittsburgh modified TNM criteria. Liver Transpl 2002;8:765-774.

4. Wiesner RH, Freeman RB, Mulligan DC. Liver transplantation for hepatocellular cancer: the impact of the MELD allocation policy. Gastroenterology 2004;127:S261-S267.

5. Sharma P, Balan V, Hernandez JL, Harper AM, Edwards $\mathrm{EB}$, Rodriguez-Luna H, et al. Liver transplantation for hepatocellular carcinoma: the MELD impact. Liver Transpl 2004; 10:36-41.

6. Eurotransplant Newsletter 2003;189:5.

7. Bruix J, Sherman M, Llovet JM, Beaugrand M, Lencioni R, Burroughs AK, et al. Clinical management of hepatocellular carcinoma. Conclusions of the Barcelona-2000 EASL conference. European Association for the Study of the Liver. J Hepatol 2001;35:421-430.

8. Majno P, Giostra E, Morel P, Hadengue A, Mentha G; Geneva Liver Cancer Study Group. Management of hepatocellular carcinoma in the waiting list before liver transplantation. J Hepatol 2005;42:S134-S143.

9. Pugh RNH, Murray-Lyon IM, Dawson JL, Pietroni MC, Williams R. Transection of the oesophagus for bleeding oesophageal varices. Br J Surg 1973;60:646-649.

10. Wiesner R, Edwards E, Freeman R, Harper A, Kim R, Kamath $\mathrm{P}$, et al. Model for End-Stage Liver Disease (MELD) and allocation of donor livers. Gastroenterology 2003; 124:91-96.

11. United Network for Organ Sharing. Available at: http:// www.unos.org. Accessed December 5, 2007.

12. Yao FY, Bass NM, Ascher NL, Roberts JP. Liver transplantation for hepatocellular carcinoma: lessons from the first year under the Model of End-Stage Liver Disease (MELD) organ allocation policy. Liver Transpl 2004; 10:621-630.

13. Liver (including intrahepatic bile ducts). In: Green FL, Page DL, Fleming ID, American Joint Committee on Cancer, American Cancer Society, eds. AJCC Cancer Staging Manual. 6th ed. New York: Springer-Verlag; 2002:131144.

14. Edmonson HA, Steiner PE. Primary carcinoma of the liver: a study of 100 cases among 48.900 necropsies. Cancer 1954;7:462-503.

15. Cox DR, Oakes D. Analysis of survival data. London: Chapman and Hall; 1984

16. Hosmer DW, Hosmer T, Le Cessie S, Lemeshow S. A comparison of goodness-of-fit tests for the logistic regression model. Stat Med 1997; 16:965-980.

17. Abacus concepts. Survival tools for Stat View. Berkeley, CA: Abaccus Concepts; 1994.

18. Llovet JM, Fuster J, Bruix J. Intention-to-treat analysis of surgical treatment for early hepatocellular carcinoma: resection versus transplantation. Hepatology 1999;30: 1434-1440.

19. Yao FY, Bass NM, Nikolai B, Davern TJ, Kerlan R, Wut V, et al. Liver transplantation for hepatocellular carcinoma: analysis of survival according to the intention-to-treat principle and dropout from the waiting list. Liver Transpl 2002;8:873-883.

20. Maddala YK, Stadheim L, Andrews JC, Burgart LJ, Rosen CB, Kremers WK, Gores G. Drop-out rates of patients with hepatocellular cancer listed for liver transplantation: outcome with chemoembolization. Liver Transpl 2004;10:449455.

21. Roayaie S, Llovet JM. Liver transplantation for hepatocellular carcinoma: is expansion of criteria justified? Clin Liver Dis 2005;9:315-328.

22. Yamashiki N, Gaynor JJ, Kato T, Reddy KR, Sobhonslidsuk A, Levi D, et al. Competing risks analysis of predictors of delisting owing to tumour progression in liver transplant candidates with hepatocellular carcinoma. Am J Transplant 2004;4:774-781.

23. Fisher RA, Maluf D, Cotterell AH, Stravitz T, Wolfe L, Luketic V, et al. Non-resective ablation therapy for hepatocellular carcinoma: effectiveness measured by intention-to-treat and dropout from liver transplant waiting list. Clin Transplant 2004; 18:502-512.

24. Ravaioli M, Grazi GL, Ballardini G, Cavrini G, Ercolani G, Cescon M, et al. Liver transplantation with the MELD system: a prospective study from a single European center. Am J Transplant 2006;6:1572-1577.

25. Huo TI, Wu JC, Lin HC, Lee FY, Hou MC, Hunag YH, et al. Determination of the optimal Model for End-Stage Liver Disease score in patients with small hepatocellular carcinoma undergoing loco-regional therapy. Liver Transpl 2004;10:1507-1513.

26. Degre D, Bourgeois N, Boon N, Le Moine O, Louis H, Donckier V, et al. Aminopyrine breath test compared to the MELD and Child-Pugh scores for predicting mortality among cirrhotic patients awaiting liver transplantation. Transpl Int 2004;17:31-38.

27. Everson GT. MELD: the answer or just more questions? Gastroenterology 2003;124:251-254.

28. Olthoff KM, Brown RS Jr, Delmonico FL, Freeman RB, McDiarmid SV, Merion RM, et al. Summary report of a national conference: evolving concepts in liver allocation in the MELD and PELD era. December 8, 2003, Washington, DC, USA. Liver Transpl 2004;10:A6-A22.

29. Libbrecht L, Bielen D, Verslype C, Vanbeckevoort D, Pirenne J, Nevens F, et al. Focal lesions in cirrhotic explant livers: pathological evaluation and accuracy of pretransplantation imaging examinations. Liver Transpl 2002;8:749-761.

30. Freeman RB, Mithoefer A, Ruthazer R, Nguyen K, Schore A, Harper A, Edwards E. Optimizing staging for hepatocellular carcinoma before liver transplantation: a retrospective analysis of the UNOS/OPTN database. Liver Transpl 2006;12:1504-1511.

31. Caturelli E, Solmi L, Anti M, Fusilli S, Roselli P, Andriulli $A$, et al. Ultrasound guided fine needle biopsy of early hepatocellular carcinoma complicating liver cirrhosis: a multicentre study. Gut 2004;53:1356-1362.

32. Bruix J, Sala M, Llovet JM. Chemoembolization for hepatocellular carcinoma Gastroenterology 2004;127:S179S188.

33. Otto G, Herber S, Heise M, Lohse AW, Monch C, Bittinger $\mathrm{F}$, et al. Response to transarterial chemoembolization as a biological selection criterion for liver transplantation in hepatocellular carcinoma. Liver Transpl 2006;12:12601267.

34. Adam R, Azoulay D, Castaing D, Eshkenazy R, Pascal G, Hashizume K, et al. Liver resection as a bridge to transplantation for hepatocellular carcinoma on cirrhosis: a reasonable strategy? Ann Surg 2003;238:508-518.

35. Llovet JM, Vilana R, Bru C, Bianchi L, Salmeron JM, Boix 
L, et al. Increased risk of tumour seeding after percutaneous radiofrequency ablation for single hepatocellular carcinoma. Hepatology 2001;33:1124-1129.

36. Bruix J, Llovet JM. Prognostic prediction and treatment strategies in hepatocellular carcinoma. Hepatology 2002; 35:519-524.

37. Shetty K, Timmins K, Brensinger C, Furth EE, Rattan S, Sun W, et al. Liver transplantation for hepatocellular carcinoma validation of present selection criteria in predicting outcome. Liver Transpl 2004;10:911-918.

38. Herrero JI, Sangro B, Quiroga J, Pardo F, Herraiz M, Cienfuegos JA, Prieto J. Influence of tumour characteristics on the outcome of liver transplantation among patients with liver cirrhosis and hepatocellular carcinoma. Liver Transpl 2001;7:631-636.

39. Leung JY, Zhu AX, Gordon FD, Pratt DS, Mithoefer A, Garrigan K, et al. Liver transplantation outcomes for early-stage hepatocellular carcinoma: results of a multicenter study. Liver Transpl 2004;10:1343-1354.

40. Vauthey JN, Ribero D, Abdalla EK, Jonas S, Bharat A,
Schumacher G, et al. Outcomes of liver transplantation in 490 patients with hepatocellular carcinoma: validation of a uniform staging after surgical treatment. J Am Coll Surg 2007;204:1016-1027.

41. Busuttil RW, Farmer DG, Yersiz H, Hiatt JR, McDiarmid SV, Goldstein LI, et al. Analysis of long-term outcomes of 3200 liver transplantations over two decades: a singlecenter experience. Ann Surg 2005;241:905-916.

42. Bruix J, Llovet JM. Prognostic prediction in HCC: did anyone expected to be easy? Hepatology 2004;39:551552.

43. Marsh JW, Casavilla A, Iwatsuki S, Dvorchik I, Subotin M, Balan V, et al. Predicting the risk of tumor recurrence following transplantation for hepatocellular carcinoma. Hepatology 1997;26:1689-1691.

44. Vivarelli M, Cucchetti A, Piscaglia F, La Barba G, Bolondi L, Cavallari A, Pinna AD. Analysis of risk factors for tumor recurrence after liver transplantation for hepatocellular carcinoma: key role of immunosuppression. Liver Transpl 2005; 11:497-503. 